surements of Aerodynamic Forces on an Oscillating Airfoil. Proceedings of the Thirteenth Japan National Congress for Applied Mechanics, 1963.

59）鉒口展広，坂田弘：吊り穚の耐風安定性に関する基碟 研究拉よご続報，日本航空学会誌，第 13 巻，第 133 号、昭和 40 年 2 月， $27-36$ 頁および第 14 巻，第 146 号, 昭和 41 年 3 月， 65-75 頁.

\section{略壾号}

IAS Institute of Aeronautical Sciences

AIAA American Institute of Aeronautics and Astronautics

JAS Journal of the Aeronautical Sciences

JAHS Journal of the American Helicopter Society

\title{
ヘリコプタの動安定微係数* \\ Dynamic Stability Derivatives of Helicopter
}

東

昭**

Akira Azuma

ヘリコプタの安定微係数は回転翼の寄与する部分が 大きく，固定翼機の主翼のそれに比へて理論的にその 值を推定することが極めて難かしい，したがって安定 徽係数の決定にはなるべく模型の風洞実験が望ましい が，残念ながら特に動安定微係数の評価は，模型実驗 であ複雑で色々な要因が混ざり合い，それぞれの微係 数を部分微係数の形で取り出すととは容易でない．回 転翼機の空力特性を推定することの困難さは尃ら翼翅 の放出する洞が簡単化した理想的な場合です固定翼機 のそれに比へて複雑であるてとおよび翼翅の各要素の 変位が同樣の理由で正確に決定されないためで, 通 常, 安定微係数の計算では運動量理諭に基つく一様吹 き下ろし流を考えている. 各翼翅加ら出る回転螺旋面 上の非定常の渦の分布は変動荷重の計算とか騷音の計 算にのみ用いられるのが普通である.

特にホバリング飛行中の回転翼の摇動では，翼翅の 放出渦への接近で局所的な強い吹き下ろし流の影響を 受けるために，一樣な吹き下ろし流住基つく理論計算 值よりも翼翅の揚力傾斜を著しく低下させたような結 果が予想される. したがってててでは主として理論的 な解析で何がどういう風に効いているかの解説にとど わ，実際の数值の具体的な検討は今後の研究にまつこ とを期待する.

回転翼の安定微係数を求めるに当たって，固定翼の それと最も著しい違いは，回転翼が機体の運動之別の 回転自由度を有すること，すなわち翼がフラッピング 運動をすることである．ヒンジレスまたはリジッド． ロータと呼ばれる回転翼も実際には翼翅の可撓性を利 用していて，翼の付け根近くにフラッピング・ヒンシ があることに相当し，こてにある程度のばね常数を持 ったばねが取り付けられているようなオフセット・ヒ

\footnotetext{
* 昭和 46 年 7 月 1 日原稿受理
}

** 東京大学宇宙航空研究所
ンジ付きの一種の関節式回転翼と見做せる

回転翼の機体モーメントへの寄与は, 推力線の重心 からのずれによるモーメント，フラッピング軸に㗢く 空気力と慣性力のヒンジ・オフセットによるモーメン ト，フラッピング軸に街くばね力に基つくとーメント およびその吹き下ろし流の胴体之尾翼への干啮とから なる。

このため関連する独立変数による各空力係数の微分 はそれら諸量により偏微分された直接頃とフラッピン グ角と吹き下ろし流を媒介変数として偏微分のとられ た関接項とからなる。

以下具体的に，例として単一回転翼を持ったヘリコ プタの縦摇と横摇安定に関与する主要な項を列記して 説明しょう3).

縦摇と横摇の安定に関連する微係数で一番重要でし かもその評価が難かしいものに減衰係数 $d C_{M Y} / d(q)$ S) と $d C_{M z} / d(p / \Omega)$ がある.

回転翼のハブ周りのモーメント

$$
\begin{aligned}
& \frac{d C_{M_{Y}}}{d(q / \Omega)}=\frac{\partial C_{M_{Y}}}{\partial(q / \Omega)}+\frac{\partial C_{M_{Y}}}{\partial \beta_{1 C}} \frac{\partial \beta_{1 C}}{\partial(q / \Omega)}+\frac{\partial C_{M Y}}{\partial \beta_{1 s}} \frac{\partial \beta_{1 S}}{\partial(q / \Omega)} \\
& \frac{d C_{M_{x}}}{d(p / \Omega)}=\frac{\partial C_{M_{x}}}{\partial(p / \Omega)}+\frac{\partial C_{M_{x}}}{\partial \beta_{1 c}} \frac{\partial \beta_{1 C}}{\partial(p / \Omega)}+\frac{\partial C_{M_{x}}}{\partial \beta_{1 s}} \frac{\partial \beta_{1 s}}{\partial(p / \Omega)}
\end{aligned}
$$

第 1 項はフラッピング角に無関係な, フラッピング 軸における空気力の積分に基つく項で

$$
\begin{aligned}
& \partial C_{M_{\mathbf{X}}} / \partial(q / \Omega)=-x_{\beta} \frac{1}{2} a \sigma\left(B^{3} / 6\right) \\
& \partial C_{M_{\mathbf{X}}} / \partial(p / \Omega)=-x_{\beta} \frac{1}{2} a \sigma\left(B^{3} / 6\right)
\end{aligned}
$$

で与えられる． $x_{\beta}$ は回転翼半径で無次元化された七 ンシの位置で，この值が大きい程減衰係数も大とな る. この項はしかしホバリング時には特に翼が前後 または左右の位直で吹き下ろし中の渦層に近つくの で，そとでの揚力減少は緹摇または横摇れの動きで得 
られる揚力を相当減らしてしまう.このため揚力傾斜 $a$ が著しく減った形となり，通常用いられる $a=5.73$ はその $1 / 4$ 程度におちるととが高沢》似より指摘され ている.あっとも小型の模型実験では元来 $a$ はとても 5.73 などという大きい值は期待出来ない5).

第 2 項はそれぞれ次式で与えられる.

$$
\begin{gathered}
\partial C_{M Y} / \partial \beta_{1 C}=-(1 / 2)\left\{\nu x_{\beta} \bar{x}+\left(b k_{\beta} / \rho S R^{3} \Omega^{2}\right)\right\} \\
\partial C_{M x} / \partial \beta_{1 S}=-(1 / 2)\left\{\nu x_{\beta} \bar{x}+\left(b k_{\beta} / \rho S R^{3} \Omega^{2}\right)\right\} \\
\partial \beta_{1 C} / \partial(q / \Omega)=\left\{1 /\left(K_{\beta}{ }^{2}+K_{\beta^{2}}-\frac{1}{4} K_{3} K_{\beta} \mu^{2}\right)\right\} \\
\quad \times K \beta\left(2+K_{\beta}\right) \\
\partial \beta_{1 S} / \partial(p / \Omega)=\left\{1 /\left(K_{\beta}{ }^{2}+K_{\beta^{2}}+\frac{1}{4} K_{3} K_{\beta} \mu^{2}\right)\right\} \\
\quad \times K_{\beta}\left(2+K_{\beta}\right)
\end{gathered}
$$

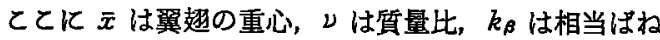
常数， $K_{\beta}$ はそれを無次元化したすの，そして $K_{\beta}$ と $K_{3}$ は空気力之慣性力の比である.

$$
\begin{aligned}
& \bar{x}=\int_{R x_{\beta}}^{R} r d m / R m, \quad \nu=b m / \rho S R \\
& K_{\beta}=\left\{\left(k_{\beta} / m R^{2} \Omega^{2}\right)+x_{\beta} \bar{x}\right\} /\left(I_{\beta} / m R^{2}\right) \\
& K_{\beta}=\gamma\left(\frac{B^{4}}{8}-\frac{B^{3}}{6} x_{\beta}\right)=\frac{\rho a c R^{4}}{I_{\beta}}\left(\frac{B^{4}}{8}-\frac{B^{3}}{6} x_{\beta}\right) \\
& K_{3}=\frac{\rho a c R^{4}}{I_{\beta}}\left(\frac{B^{2}}{4}-\frac{B}{2} x_{\beta}\right)
\end{aligned}
$$

フラッピング角によるモーメントの変化， $\partial C_{M Y} /$ $\partial \beta_{1 C}$ 之 $\partial C_{M \mathbb{X}} / \partial \beta_{1 s}$ の中第 1 項は翼翅化㗢く慣性力（遠 心力）が回転面の傾きで発生するモーメントを示し， 第 2 項はばね社つくモーメントである. 第 1 項は七 ンジ・オフセットを大にしかつ翼翅の質量を增すてと で，また第 2 項はば和を強くすることでその值を大き く出来る.

一方機体の角速度に基つくフラッピング角の変化, つまり回転翼の機体角速度に対するおくれの項は，ば ねあヒンシ・・フフットあ十分小さいときは大きくす るととが望ましいがある程度以上大になると翼避の質 量とと屯に悪い方働くようになる。したがって適当 なばねの強さがあるはずで，そのうまい選択が元来之 しいこの減衰係数を高める一因となり得る. また進行 率 $\mu$ は縦摇では良い方にまた横摇では悪い方に効く．

第 3 項は互に交錯した項でそれぞれ次式のように表 わされる。

$$
\begin{aligned}
& \partial C_{M_{Y}} / \partial \beta_{1 s}=x_{\beta} \frac{1}{2} a \sigma\left(\frac{B^{3}}{6}+\frac{B}{8} \mu^{2}\right) \\
& \partial C M_{X} / \partial \beta_{1 C}=-x_{\beta} \frac{1}{2} a \sigma\left(\frac{B^{3}}{6}-\frac{B}{8} \mu^{2}\right) \\
& \partial \beta_{1 s} / \partial(q / \Omega)=\left(K_{\beta^{2}}-2 K_{\beta}\right) \\
& \quad \div\left(K_{\beta}^{2}+K_{\beta}+\frac{1}{4} K_{3} K_{\beta} \mu^{2}\right)
\end{aligned}
$$

$$
\begin{array}{r}
\partial \beta_{1 c} / \partial(p / \Omega)=-\left(K_{\beta^{2}}-2 K_{\beta}\right) \\
\quad \div\left(K_{\beta}^{2}+K_{\beta^{2}}-\frac{1}{4} K_{3} K_{\dot{\beta}} \mu^{2}\right)
\end{array}
$$

これらは機体の縦摇による回転翼の横擇れと機体の 横摇れによる回転翼の縦摇から来るあので，フラッピ ング角による $\partial C_{M Y} / \partial \beta_{1 s}$ と $\partial C_{M x} / \partial \beta_{1 c}$ は空気力の 皘分された剪断すがヒンジ周りに作るモーメントであ る. 揚力傾斜 $a$ はやはりあまり大きい值は期待出来そ うにない. 機体角速度に基つくフラッピング角の変化， $\partial \beta_{1 s} / \partial(q / \Omega)$ と $\partial \beta_{1 c} / \partial(p / \Omega)$ はばねが弱いときはほ 1 で，したがって第 3 項全体としてはいずれす正で不安 定の悪い方に効いている. しかしいずれにしるさきの 第 2 項に比へててモーメントトとしての効きは小さい．

回転翼の水平力 ( $\boldsymbol{H}$ カと $\boldsymbol{Y}$ カ) の作るモーメント これは推力線の傾きの成分に相当してハブの重心から の高さに比例し，回転翼シャフトの傾きが零のとき次 式で与えられる.

$$
\begin{aligned}
& (h / R) \frac{d C_{H}}{d(q / \Omega)}=(h / R)\left\{\frac{\partial C_{H}}{\partial(q / \Omega)}+\frac{\partial C_{H}}{\partial \beta_{1 c}} \frac{\partial \beta_{1 c}}{\partial(q / \Omega)}\right. \\
& \left.\quad+\frac{\partial C_{H}}{\partial \beta_{1 s}} \frac{\partial \beta_{1 s}}{\partial(q / \Omega)}\right\} \\
& (h / R) \frac{d C_{Y}}{d(p / \Omega)}=(h / R)\left\{\frac{\partial C_{Y}}{\partial(p / \Omega)}+\frac{\partial C_{Y}}{\partial \beta_{1 s}} \frac{\partial \beta_{1 C}}{\partial(p / \Omega)}\right. \\
& \left.\quad+\frac{\partial C_{Y}}{\partial \beta_{1 c}} \frac{\partial \beta_{1 C}}{\partial(p / \Omega)}+\frac{\partial C_{Y}}{\partial \beta_{0}} \frac{\partial \beta_{0}}{\partial(p / \Omega)}\right\}
\end{aligned}
$$

第 1 項は

$$
\begin{aligned}
& \partial C_{H} / \partial(q / \Omega)=\frac{1}{2} a \sigma\left\{-\frac{B^{2}}{16} \mu \theta_{1 c}-\frac{B^{3}}{6} \beta_{0}\right. \\
& \left.+\frac{B^{2}}{16} \mu \beta_{1 s}\right\} \\
& \partial C_{Y} / \partial(p / \Omega)=\frac{1}{2} a \sigma\left\{\frac{B^{2}}{16} \mu \theta_{1 c}-\frac{B^{3}}{6} \beta_{0}\right. \\
& \left.-\frac{5}{16} B^{2} \mu \beta_{1 s}\right\}
\end{aligned}
$$

で与えられ，通常目である. しかし揚力傾斜 $a$ は特に ホバリング時には前同様减少してしまう， $\mu$ の大きい とき横サイクリック・ピッチ $\theta_{1 C}$ のとり方で $C_{Y}$ の方 が正になる可能性がある.

第 2 項は $\partial C_{H} / \partial \beta_{1 c}$ 亡 $\partial C_{Y} / \beta_{1 S}$ の方が

$$
\begin{aligned}
\partial C_{H} / \partial \beta_{1 C}= & -\frac{1}{2} a \sigma\left\{\frac{B^{3}}{3} \theta_{0}+\frac{B^{2}}{4} \mu \theta_{1 s}-\frac{3}{4} B^{2} \lambda\right. \\
& \left.-\frac{1}{2} B^{2} \mu \beta_{1 C}\right\}+\frac{1}{2} \nu \bar{x} \beta_{0} \\
\partial C_{Y} / \partial \beta_{1 S}= & -\frac{1}{2} a \sigma\left\{\left(\frac{B^{3}}{3}+\frac{B}{2} \mu^{2}\right) \theta_{0}+\frac{1}{2} B^{2} \mu \theta_{1 S}\right. \\
& \left.-\frac{3}{4} B^{2} \lambda-\frac{1}{4} B^{2} \mu \beta_{1 C}\right\}+\frac{1}{2} \nu \bar{x} \beta_{0}
\end{aligned}
$$

と書ける. 前半の空気力の方の項は，速度の小さいと 
きは負となり减亳力として略く，しかし速度が大にな ると縱サイクリック・ピッチ $\theta_{1 s}$ は目となりかつ流入 比入む正で大になるので（特に上昇時はこの入が大き くなる）忢い方すなわち減衰力とはならなくなる、乙 机反してオートロティションでは $\theta_{0}$ が小さくなる が入が負となるので減衰項として効くようになる6

後半の愪性力の項はュニング角 $\beta_{0}$ に比例して正と なり非減衣項である．との点ではコニング角が小さい 方が良い。

$\partial \beta_{1 c} / \partial(q / \Omega)$ と $\partial \beta_{1 s} / \partial(p / \Omega)$ については, 前述した とおり.

第 3 項は $\mu$ の大きいときを除いて通営省略される.

$C_{Y}$ の方の第 4 項はコニング角 $\beta_{0}$ に基つく．とれは $C_{H}$ の方では $\partial \beta_{0} / \partial(q / \Omega)$ がほほ零と見做せるので書い てない.

$$
\begin{gathered}
\partial C_{Y} / \partial \beta_{0}=\frac{1}{2} a \sigma\left\{-\frac{3}{4} B^{2} \mu \theta_{0}-\left(\frac{B^{3}}{6}+\frac{B}{2} \mu^{2}\right) \theta_{1 s}\right. \\
\left.+\frac{3}{2} B \mu \lambda+\left(-\frac{B^{3}}{6}+B \mu^{2}\right) \beta_{1 c}\right\}+\frac{1}{2} \nu \bar{x} \beta_{1 s} \\
\partial \beta_{0} / \partial(p / \Omega)=\frac{1}{4}\left(\rho a C R^{4} / I_{\beta}\right)\left(\frac{B^{3}}{3}-\frac{B^{2}}{2} x_{\beta}\right) \mu \\
\quad \div\left\{1+\left(k_{\beta} / I_{\beta} \Omega^{2}\right)\right\}
\end{gathered}
$$

上の項がホバリングでは零なので効かない，速度の大 きいときは $\theta_{1 s}$ が負で大になり，特に上昇時には $\lambda$ あ 正で大となるので非減衰になり得る.

水平安定板の作る稌摇モーメント 固定翼機同様水 平尾翼（面皘 $S_{h}$, 揚力傾斜 $a_{h}$ ) が重心から $l_{h}$ の距 離にあるときそのモーメント微係数は

$$
\begin{aligned}
& -\left(l_{h} / R\right) \frac{d C_{L}}{d(q / \Omega)} \mu^{2}=-\eta_{h}\left(l_{h} / R\right)^{2} \frac{1}{2}\left(S_{h} / S\right) a_{h} \mu \\
& -\left(l_{h} / R\right) \frac{d C_{L}}{d(\dot{\alpha} / \Omega)} \mu^{2}=-\eta_{h}\left(l_{h} / R\right)^{2} \\
& \times \frac{1}{2}\left(S_{h} / S\right) a_{h}\left\{\left(v / v_{0}\right) \frac{1}{2} a \sigma\left(B^{2} / 4\right)\right\}
\end{aligned}
$$

で与えられる、 $\eta_{b}$ は動圧比で，てれらは速度の大き いときに効いて来る減衰項である．上の項は角速度に 基つくあの，下の項は吹き下ろしの尾翼へのおくれの 時間差が効く項で $v / v_{0}$ は尾翼位置での吹き下ろしと 回転翼中心でのそれとの比である.

尾部回転翼の作る横㨘モーメント 尾部回転翼が作 る動的横摇モーメントには横摇角速度によるあのと偏 摇角速度によるあのとがある。

$$
\eta_{t}\left(h_{t} / R\right) \frac{d C_{T t}}{d(p / \Omega)}=\eta_{t}\left(h_{t} / R\right)\left\{\frac{\partial C_{T t}}{\partial(p / \Omega)}+\frac{\partial C_{T t}}{\partial \lambda_{t}}\right.
$$

$$
\begin{gathered}
\left.\times \frac{\partial \lambda_{t}}{\partial(p / \Omega)}\right\}=\eta_{t}\left(h_{t} / R\right)\left(\frac{1}{2} a \sigma\right)_{t}\left\{\frac{B^{2}}{4} \mu_{t}\right. \\
\left.-\frac{1}{2} B^{2}\left(h_{t} / R\right)\right\} \\
\eta_{t}\left(h_{t} / R\right) \frac{d C_{T_{t}}}{d(r / \Omega)}=\eta_{t}\left(h_{t} / R\right)\left\{\frac{\partial C_{T_{t}}}{\partial \lambda_{t}} \frac{\partial \lambda_{t}}{\partial(r / \Omega)}\right\} \\
=\eta_{t}\left(h_{t} / R\right)\left(l_{t} / R\right)\left\{\frac{1}{2}(a \sigma)_{t}\left(\frac{1}{2} B^{2}\right)\right\}
\end{gathered}
$$

ここにク。は回転翼の先端速度の尾翼と主翼の比で, 下指標 $t$ 大で尾翼の值を示す. 前者は減哀項として働 き，後者は偏摇角速度に対して正の横摇モーメントを 生ずることを示している. 前進飛行時の横摇運動は推 力変化を生じ, 尾部回転翼の坦合これがモーメントに 効いて来る. 上の項の第 1 項がそれに相当する.

以上翼素理論から導かれた動安定微係数を列挙した が, 具体的な数值についてはててでは触れなかった. 通常関節式回転翼はこれらの值があまり大きくないの で, 補助の安定増大装置として例えばベルのスタビラ

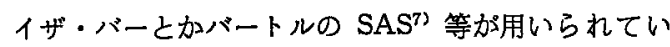
る. ヒンシンスの回転翼は制御能力の增大ととあに動 安定微保数す大きくなっているが，一方とてでは述へ なかった迎角不安定も増大している.

\section{参考文献}

1) Young, Maurice I. : A Simplified Theory of Hingeless Rotors with Application to Tandem Helicopters. Proceedings of the Eighteenth Annual National Forum of the American Helicopter Society, 1962, pp. 38-45.

2) Bramweli, A. R.S.: A Method for Calculating the Stability and Control Derivatives of Helicopter with Hingeless Rotors. Research Memorandum Aero 69/4, The City University, London, 1970.

3) Azuma, Akira: Dynamic Analysis of the Rigid Rotor System. Journal of Aircraft, Vol. 4, No. 3, 1967, pp. 203-209.

4) 高沢金吾：リシッドヘリコプタロータのホバリングに 於けるピッチダンピングについて，東京大学大学院工 学系航空コース学位論文, 1971.

5) Payne, P. R. : Helicopter Dynamics and Aerodynamics. Sir Isaac Pitman \& Sons, Ltd., London, 1959 (Chapter I).

6) Amzr, Kenneth B.: Theory of Helicopter Damping in Pitch or Roll and a Comparison with Flight Measurements. NACA TN 2136, 1950.

7) 東昭：自動安定，日本航空学会誌，Vol. 11, No. 110, 1963, pp. 69-81. 